Wegen Müdigkeit und Parästhesien zum Arzt

\title{
Überraschungsbefund: Fett aus dem Lot
}

W. Richter

\begin{abstract}
Stephan G., 46 Jahre alt, sucht den Hausarzt wegen seit Wochen bestehender starker Müdigkeit und wiederkehrenden Parästhesien an den Füßen auf. Die Anamnese und die klinische Untersuchung ergeben außer einem mäßig erhöhten Blutdruck (150/95 mmHg) keine auffälligen Befunde $(180 \mathrm{~cm}, 81 \mathrm{~kg}$, Familienanamnese für KHK negativ).
\end{abstract}

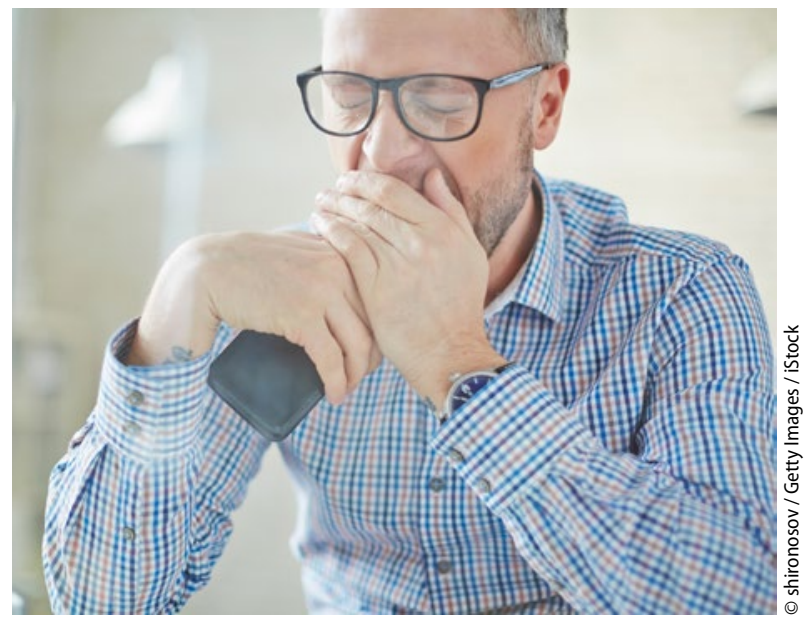

- Bei der Blutuntersuchung finden sich:

- Cholesterin: $438 \mathrm{mg} / \mathrm{dl}$

- Triglyzeride: $1.623 \mathrm{mg} / \mathrm{dl}$

- HDL-Cholesterin: $21 \mathrm{mg} / \mathrm{dl}$

- Chylomikronen: +++

\section{Diagnose}

Chylomikronämie-Syndrom (Triglyzeride über $1.000 \mathrm{mg} / \mathrm{dl}$ erhöht, Chylomikronen schon beim Stehenlassen des Blutplasmas oder -serums nachweisbar, klinische Symptome).

\section{Therapie}

Akut möglichst rasch die Triglyzeridkonzentration unter $1.000 \mathrm{mg} / \mathrm{dl}$ senken, um insbesondere die Gefahr für eine akute Pankreatitis, andere schwere abdominelle Schmerzzustände durch Mikrozirkulationsstörungen im Bereich des Dünndarms oder durch eine Kapselspannung von Leber und Milz auszuschalten. Dazu eignet sich am besten eine Nulldiät (3 1 kalorienfreie Flüssigkeit pro Tag) für 1-3 Tage. Damit kann pro 24 Stunden eine Absenkung der Triglyzeride um jeweils $50 \%$ erreicht werden.

Danach Dauertherapie. Bei abdominellen Beschwerden sollte die Einweisung in eine Klinik nicht hinausgeschoben werden, da dort ggf. durch eine Plasmapherese die Komplikationen abgemildert oder verhindert werden können.

Cave: Bei V.a. Pankreatitis nicht die a-Amylase im Serum bestimmen, da bei erheblicher Hypertriglyzeridämie meist falsch niedrige Werte gemessen werden. Auch daran denken, dass bei Messung der Elektrolyte im nicht-delipidierten Serum oder Plasma diese falsch niedrig bestimmt werden und die tatsächliche Konzentration pro $1.000 \mathrm{mg} / \mathrm{dl}$ Triglyzeride um jeweils 2-5\% höher liegt.

\section{Sieben Tage später}

Werte nach zwei Tagen Nulldiät, Alkoholverzicht und weniger Kohlenhydrate:

- Cholesterin: $331 \mathrm{mg} / \mathrm{dl}$

- Triglyzeride: $241 \mathrm{mg} / \mathrm{dl}$

- HDL-Cholesterin: $31 \mathrm{mg} / \mathrm{dl}$

- LDL-Cholesterin: 252 mg/dl.

In der Abbauphase einer Hypertriglyzeridämie steigt vorübergehend das LDLCholesterin an. Wird dies nicht bedacht, wird evtl. fälschlicherweise eine LDLHypercholesterinämie diagnostiziert und therapiert.

Eine Hypertriglyzeridämie ist ohne entsprechende Ernährungstherapie nicht wirkungsvoll zu behandeln. Die Unterstützung des Patienten durch einen einschlägig erfahrenen Ernährungstherapeuten ist dabei sehr zu empfehlen.

\section{Ernährungsumstellung}

- Festlegung des Energiegehalts der Kost

- Aufteilung in fünf Mahlzeiten pro Tag (um die Leber nicht mit einem großen Batch zu überlasten)

- Normales Körpergewicht - falls erforderlich - langsam anstreben (max. Gewichtsabnahme/Woche: $0,5 \mathrm{~kg}$ )

- Vermehrte körperliche Aktivität, aber kein extremer Ausdauersport (wegen des vermehrten Zustroms von Fettsäuren zur Leber).
- Verzicht auf Alkohol. Das reicht meist aus, um die Hypertriglyzeridämie zu normalisieren. Die Menge an alkoholischen Getränken, die ein Patient bezüglich seiner Triglyzeride toleriert, ist unterschiedlich. Daher muss man mit dem Patienten über Alkoholkarenz sprechen. Sie kann einfach und überall eingehalten werden.

- Weniger Kohlenhydrate in der Kost (auf ca. 40 Energie-\% senken), um Fettverbrennung in der Leber zu steigern.

- Erhöhung des Fettanteils in der Nahrung auf 35-40\%, vorwiegend über ungesättigte Fettsäuren.

Nur bei diätetischer Compliance können Fibrate oder Omega-3-Fettsäuren vom Fisch eine sinnvolle Wirkung entfalten.

\section{Sechs Monate später (nach Ernährungstherapie)}

- Cholesterin: $196 \mathrm{mg} / \mathrm{dl}$

- Triglyzeride: $171 \mathrm{mg} / \mathrm{dl}$

- HDL-Cholesterin: $46 \mathrm{mg} / \mathrm{dl}$

- LDL-Cholesterin: $116 \mathrm{mg} / \mathrm{dl}$

- Blutdruck 130/85 mmHg.

Wichtig: Um die Gefährdung des Patienten für ein Chylomikronämie-Syndrom mit ggf. lebensgefährlichen Komplikationen zu erkennen, sollten die Triglyzeride nachmittags und nicht nüchtern gemessen werden!

\footnotetext{
$\rightarrow$ Anschrift des Verfassers: Prof. Dr. med. Werner Richter Institut für Fettstoffwechsel und Hämorheologie, Fröbelweg 8, D-91257 Pegnitz, E-Mail: ifh-richter@t-online.de
} 